\title{
DIRECT COMPARISON OF GROUND AND IN-FLIGHT MEASUREMENTS OF NEW MULTI-JUNCTION SOLAR CELL TECHNOLOGIES \\ Phillip P. Jenkins ${ }^{(1)}$, Benjamin Cho ${ }^{(2)}$, David Wilt ${ }^{(3)}$, James H. Ermer ${ }^{(4)}$, Eric Rehder ${ }^{(5)}$, Daniel Law ${ }^{(6)}$, Michael J. Krasowski $^{(7)}$, Lawrence Greer ${ }^{(8)}$ and Joseph Flatico ${ }^{(9)}$
}

\author{
(1) Naval Research Laboratory, 4555 Overlook Ave. SW, Washington, DC, USA,nrl_pv_research@nrl.navy.mil \\ (2) SolAero Technologies, 10420 Research Rd. SE Albuquerque, NM, USA, email, Benjamin_Cho@solaerotech.com \\ (3) Air Force Research Laboratory, 3550 Aberdeen Ave Kirtland AFB, NM, USA, AFRL.VSSVOrgMailbox@us.af.mil \\ (4) Boeing-Spectrolab, 12500 Gladstone Ave, Sylmar, CA, USA, email,james.h.ermer@boeing.com \\ ${ }^{(5)}$ Boeing-Spectrolab, 12500 Gladstone Ave, Sylmar, CA, USA, email, eric.m.rehder@boeing.com \\ (6) Boeing-Spectrolab, 12500 Gladstone Ave, Sylmar, CA, USA, email,daniel.c.law@boeing.com \\ (7) NASA Glenn Research Center, 21000 Brookpark Rd. Cleveland, OH, USA, email, Michael.J.Krasowski@nasa.gov \\ ${ }^{(8)}$ NASA Glenn Research Center, 21000 Brookpark Rd. Cleveland,OH, USA, email, lawrence.greer@nasa.gov \\ (9) Ohio Aerospace Institute, 22800 Cedar Point Rd. Cleveland,OH, USA, email, joseph.m.flatico@nasa.gov
}

\begin{abstract}
The pace of development for new photovoltaic structures such as the inverted meta-morphic (IMM) III$\mathrm{V}$ cells, exceeds the pace at which spectrally matched, calibrated, solar cells can be created due to the infrequent opportunities of balloon or space based calibration. As such, laboratories must rely on previous generation AM0 calibrated cells and make appropriate corrections. Equally challenging is measuring the same cells in space without a controlled laboratory environment. It is within this context, the $3^{\text {rd }}$ Forward Technology Solar Cell Experiment (FTSCE III), measured three, four and five junction advanced technology solar cells in space. This report compares the beginning-of-life in-flight measurements with the laboratory measurements made before flight.
\end{abstract}

\section{INTRODUCTION}

Historically, the technique for AM0 calibration of solar cells was to measure cells under near AM0 conditions on a high altitude balloon $(\sim 35 \mathrm{~km})$ or aircraft. Unfortunately for the world-wide solar cell community, there has not been a high-altitude balloon flight since 2005 by either NASA or CNES, the two traditional providers of these flights. Since that time, there has been an entire generation of $\mathrm{GaInP} / \mathrm{GaAs} / \mathrm{Ge}$ multijunction flight qualified cells that did not benefit from the use of AM0 calibrated reference cells. Instead, laboratories used previous generation calibrated cells, which have very similar spectral response, and applied either a spectral correction factor, or relied on high fidelity solar simulators to minimize the difference between the previous generation and current generation cells. These practices have proven to be relatively successful substantially due the fact that all cells grown on germanium substrates had very similar spectral response, and beginning-of-life (BOL) cells behave as two-junction cells with respect to current matching, because the Ge cell has a large amount of excess current. Not to understate the challenge of measuring cells without an AM0 standard, but for the most part, BOL cells grown on germanium behave as if the current is controlled by at most two junctions.

However, the next generation of the highest efficiency solar cells under development no longer have a current rich germanium bottom cell and all junctions in these new cells are much closer to current matched. Each sub cell has a narrower spectral response, making it more difficult to rely on calibration standards of previous generation cell types. It is within this context a space solar cell experiment was flown on the International Space Station (ISS) with three and four junction IMM cells as well as five-junction semiconductor bonded cells. This paper compares the in-flight BOL and preflight measurements to examine the efficacy of groundbased measurements of IMM III-V cells where no calibrated standard cell exists.

The $3^{\text {rd }}$ Forward Technology Solar Cell Experiment (FTSCE III) was deployed during the Space Shuttle STS-134 mission in May 2011, and was part of a lager mission known as the $8^{\text {th }}$ Materials on the International Space Station Experiment, MISSE-8. This experiment recorded current vs. voltage (I-V) curves and environmental conditions during each orbit. The experiment ran for 26 months and carried advanced technology cells from a variety of US suppliers. The Air Force Research Laboratory, Space Vehicles Directorate (AFRL/RVSV) and Lockheed Martin Corporation sponsored samples of laboratory solar cells such as three and four-junction IMM cells and strings from SolAero and Spectrolab, and semiconductor bonded technology (SBT) cells from Spectrolab. The particular cells highlighted in this paper were very stable over time. 


\section{CATALOG OF CELlS}

Tab.1 shows the matrix of multi-junction cells where high fidelity ground (I-V) measurements were available. Also shown is the bias condition cells were held at when not being measured. Fig. 1 shows the locations of the active solar cell samples.

\subsection{SolAero Cells}

The majority of SolAero cells were mounted on a honeycomb substrate instrumented with two temperature sensors. Most cells were encapsulated between two cover glasses (DCG), front and back, although one string was mounted using a rigid substrate CTE matched to GaAs. Two of the large area 3J-IMM cells $(7,8)$ were mounted to a sparse grid of synthetic fibers used on ATK's UltraFlex ${ }^{\text {TM }}$ solar array designs. One temperature sensor was mounted to the back of one of these cells. Details of the SolAero (formerly Emcore) FTSCE III coupons can be found in [1]. Details of the 3J-IMM and 4J-IMM cell designs (including spectral response data) are found in $[2,3]$.

\subsection{Spectrolab Cells}

The Spectrolab cells were mounted on two honeycomb substrates and fully grouted with a space-grade RTV compound. The 3J-IMM and 4J-IMM designs are similar to those in reference [4]. The SBT cells were five junction stacks, with the top three cells grown lattice matched to GaAs and the bottom two junctions matched to InP [5]. During experiment integration, one of the large area 3J-IMM cells experienced a cabling issue, which prevented any on-orbit measurements being collected on that cell.

\section{SPACE-BASED MEASUREMENTS}

The measurement electronics were developed at the NASA Glenn Research Center, for the first FTSCE, and a "build to print" with minor modifications was built for FTSCE III. A comprehensive description of the circuitry is found in [6]. The electronics were attached to a

Table 1. Listing of the III-V cells made by SolAero and Spectrolab on FTSCE III.

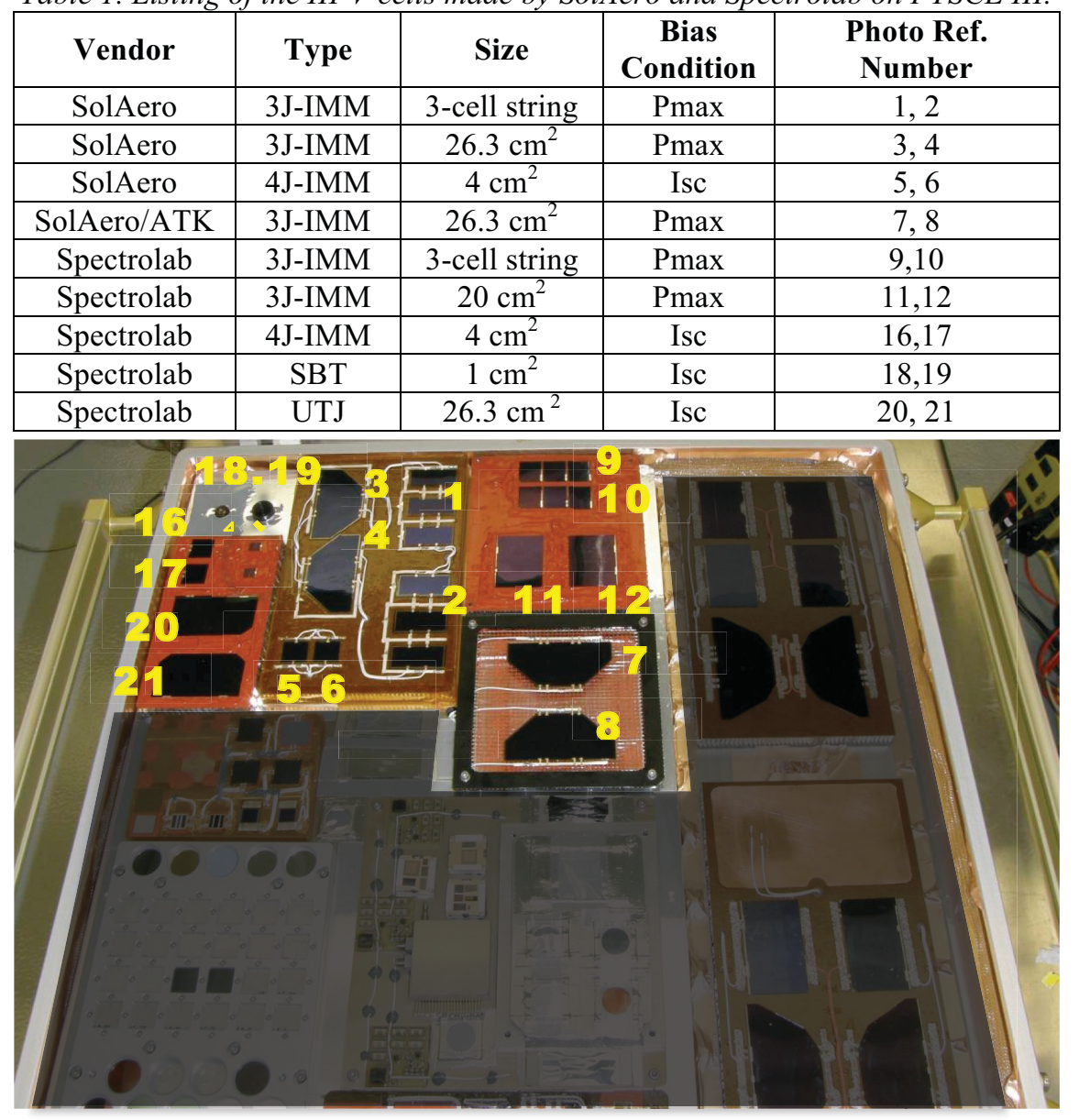

Figure 1. Photograph of the MISSE-8 zenith face highlighting Spectrolab and SolAero on FTSCE III. 


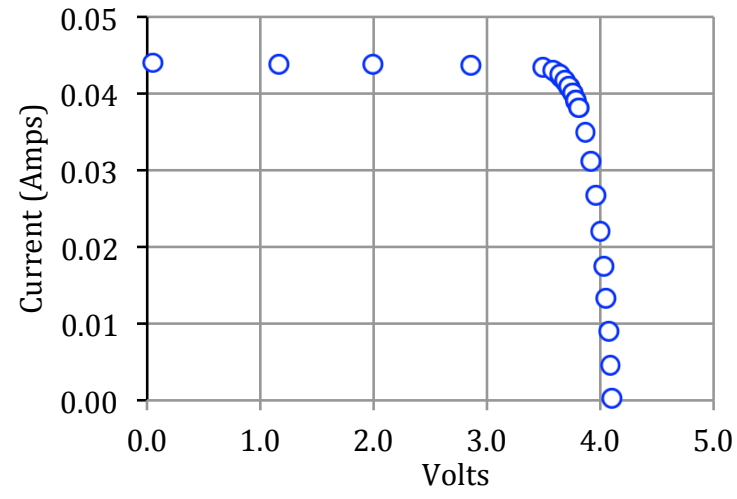

Figure 2. Typical I-V curve obtained from FTSCE III.

separate deck and stacked behind the solar panel deck (seen in Fig. 1). The electronics consisted of a central motherboard communicating with six daughter boards and relaying data to the central MISSE-8 communication board [7]. FTSCE III did not track the sun, and the best sun angle possible on each orbit was limited by the solar beta angle, which varied from +75 to -75 degree $s$ with zero crossings roughly once a month. The FTSCE III motherboard would query the six daughter boards every 30 seconds for temperature and sun angle data and record these data points every 10 minutes into a rotating buffer, where the previous orbit's worth of environmental data was kept. Using the record of the previous orbit, the motherboard used a relative set point of temperature or sun angle to acquire I-V curves.

\section{DATA ANALYSIS METHODOLOGY}

Fig. 2 is a typical I-V curve on a multi-junction cell collected by FTSCE III. Only those I-V curves with a recorded sun angle between normal incidence and $45^{\circ}$ are considered. At angles larger than $45^{\circ}$, the space station structure can create shadows or reflections. Even with this restricted angle, there are spurious data points from ISS operations such as vehicle docking or extra vehicular activities (EVAs). Only in a few cases did we attempt to remove these spurious data, as they do not significantly affect the results.

The I-V curves are reduced to the performance parameters short circuit current (Isc), open circuit voltage (Voc), current at maximum power (Imp), voltage at maximum power (Vmp), and maximum power (Pmp). These data were corrected to the same reporting condition as the pre-flight characterization by correcting for sun angle, sun-earth distance, and temperature. The voltages, Voc and Vmp, were also adjusted based on the current contribution between the measured Isc when data were collected, and the nominal AM0 current.

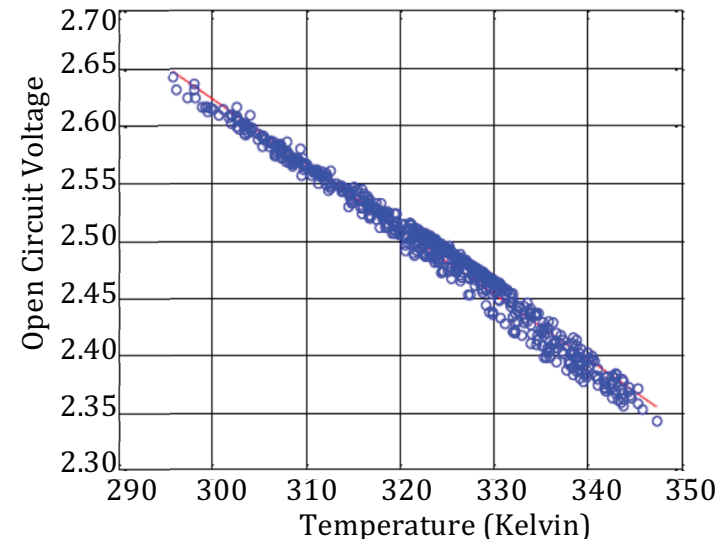

Figure 3 Typical temperature vs. open circuit voltage for a three junction cell.

Temperature measurement of these cells was particularly challenging. While the on-orbit temperature coefficient measurements of open circuit voltage show the expected linear behaviour as in Fig. 3, the absolute temperature of the cells was difficult to determine since a single temperature sensor was employed to monitor the temperature of all cells on a substrate. Furthermore, the ability of the temperature sensor to measure the temperature of the cell is problematic due to the nonmetallic face sheets the cells were attached to on the honeycomb substrate. While cell voltage is a strong function of temperature, the short circuit current (Isc) and maximum power current (Imp) are only weakly temperature dependent.

The ability to extract a high quality current temperature coefficient is made more complicated by the nature of the test conditions on-orbit. Unlike a laboratory environment, where one would maintain a constant intensity and vary the cell temperature, on-orbit the cell temperature is varied by the changing intensity due to off-pointing of the sun. Therefore, the current temperature coefficient depends on accurately correcting for cosine loss, which has its own uncertainty. Fig. 4 shows Imp vs. temperature corrected for intensity for the 3J-IMM marked "2" string in Fig.1.

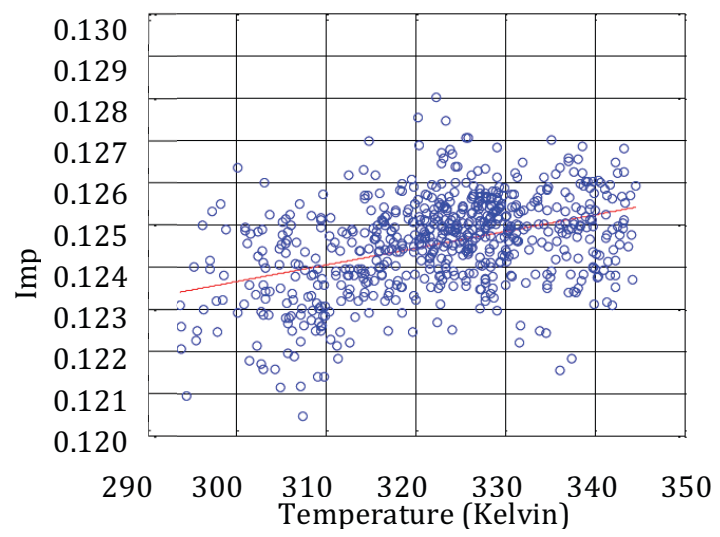

Figure 4. Imp vs. temperature for a 3J-IMM string. 


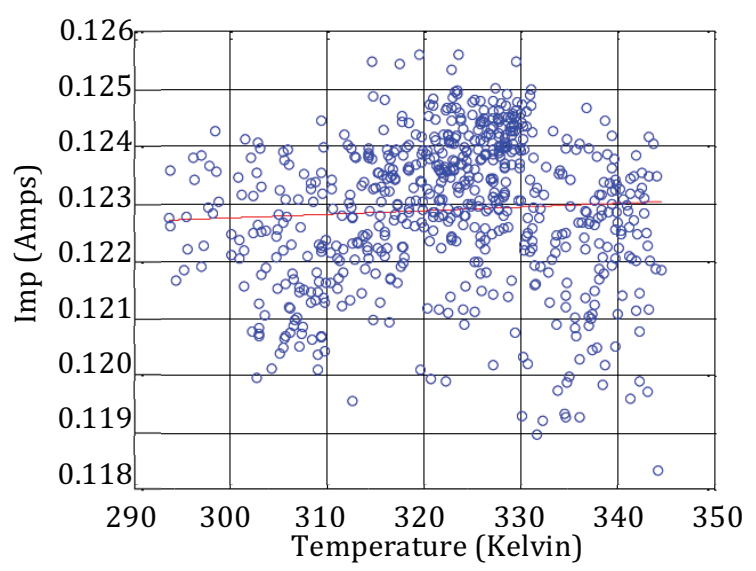

Figure 5. Imp vs temperature for another 3J-IMM string.

Fig. 5 shows the Imp vs. temperature plot for the other SolAero 3J-IMM string (number "1" in Fig. 1) showing considerably less temperature dependence than the similar string (Fig. 4). The slope of the fitted lines in the graphs of figures 3, 4 and 5 correspond to the temperature coefficients used to correct these data to standard operating conditions, and are presented explicitly later in the paper.

\section{FLIGHT VS. GROUND MEASUREMENTS}

Because the flight test articles are mounted on honeycomb substrates, large area pulse solar simulators (LAPSS) are used in laboratories to illuminate the cells for I-V measurements. The short pulse ( 1-2 milliseconds) of the LAPSS prevents the cells from heating during the measurements and the temperature of the panels can be maintained. LAPSS systems do present their own measurement challenges though.

Typically, these simulators have uniform spectral content and intensity for only one or two milliseconds. With few exceptions, laboratories do not have proper instrumentation to characterize the intensity and full spectral content of the flash pulse. This type of characterization is commonplace for continuous solar simulators, but for LAPSS systems the instrumentation is often prohibitively expensive. Without full understanding of the LAPSS spectral content, making a spectral mismatch correction is not possible [8]. Thus, it is usually the practice, to choose the closest spectrally matched calibrated cells, and hope the fidelity of the solar simulator is a good enough match to AM0 that the cell I-V curve will be accurately reproduced. A ground based calibrated isotype sub cells would be the best alternative, but are often not available for developmental cells where cell-to-cell differences can be relatively large.

Table 2. On-orbit performance parameters (BOL) and temperature coefficients compared to laboratory pre-flight ground measurements (GRD) for SolAero cells.

\begin{tabular}{|c|c|c|c|c|c|c|c|c|}
\hline $\begin{array}{c}\text { SolAero Cell } \\
\text { Type/Parameter }\end{array}$ & $\begin{array}{l}4 J- \\
\text { IMM }\end{array}$ & $\begin{array}{l}4 J- \\
I M M\end{array}$ & $\begin{array}{c}\text { 3J-IMM } \\
\text { string } \\
\text { (rigid) }\end{array}$ & $\begin{array}{c}\text { 3J-IMM } \\
\text { string } \\
\text { (DCG) }\end{array}$ & $\begin{array}{c}\text { 3J-IMM } \\
\text { Large area } \\
\text { on } \\
\text { honeycomb }\end{array}$ & $\begin{array}{c}\text { 3J-IMM } \\
\text { Large area } \\
\text { on } \\
\text { honeycomb } \\
\end{array}$ & $\begin{array}{c}\text { 3J-IMM } \\
\text { Large area } \\
\text { on } \\
\text { UltraFlex } \\
\end{array}$ & $\begin{array}{c}\text { 3J-IMM } \\
\text { Large area } \\
\text { on } \\
\text { UltraFlex }^{\mathrm{TM}} \\
\end{array}$ \\
\hline BOL Pwr Watts) & 0.165 & 0.171 & 0.965 & 0.957 & 1.049 & 1.100 & 1.091 & 1.102 \\
\hline GRD Pwr (Watts) & 0.179 & 0.179 & 0.997 & 0.996 & 1.062 & 1.112 & 1.113 & 1.106 \\
\hline BOL Voc (Volts) & 3.09 & 3.13 & 8.88 & 8.87 & 2.98 & 2.95 & 2.95 & 2.98 \\
\hline GRD Voc (Volts) & 3.237 & 3.229 & 9.048 & 9.045 & 3.000 & 3.014 & 3.018 & 3.027 \\
\hline BOL Isc (Amps) & 0.066 & 0.066 & 0.132 & 0.131 & 0.448 & 0.449 & 0.445 & 0.447 \\
\hline GRD Isc (Amps) & 0.0654 & 0.0673 & 0.131 & 0.132 & 0.441 & 0.436 & 0.445 & 0.443 \\
\hline BOL Imp (Amps) & 0.062 & 0.063 & 0.124 & 0.123 & 0.405 & 0.428 & 0.426 & 0.424 \\
\hline GRD Imp (Amps) & 0.0633 & 0.0634 & 0.124 & 0.124 & 0.402 & 0.419 & 0.422 & 0.421 \\
\hline BOL Vmp (Volts) & 2.668 & 2.719 & 7.779 & 7.782 & 2.591 & 2.571 & 2.560 & 2.598 \\
\hline GRD Vmp (Volts) & 2.829 & 2.829 & 8.03 & 8.022 & 2.645 & 2.652 & 2.638 & 2.63 \\
\hline \multicolumn{9}{|c|}{$\begin{array}{l}\text { Percent difference of the ground based measurement compared } \\
\text { to the on-orbit measurement (minus sign, red) = lower than on-orbit }\end{array}$} \\
\hline$\%$ diff Power & 8.2 & 4.7 & 3.4 & 4.0 & 1.2 & 1.0 & 2.0 & 0.4 \\
\hline$\%$ diff Voc & 4.8 & 3.2 & 1.9 & 1.9 & 0.6 & 2.1 & 2.5 & 1.5 \\
\hline$\%$ diff Isc & -1.0 & 2.0 & -0.8 & 0.8 & -1.5 & -3.0 & 0.0 & -1.1 \\
\hline$\%$ diff Imp & 2.1 & 0.6 & 0.2 & 0.9 & -0.8 & -2.1 & -1.0 & -0.8 \\
\hline$\%$ diff Vmp & 6.0 & 4.1 & 3.2 & 3.1 & 2.1 & 3.2 & 3.0 & 1.2 \\
\hline \multicolumn{9}{|c|}{ On-orbit measured temperature coefficients } \\
\hline $\operatorname{Voc}\left(\mathbf{m V} /{ }^{\circ} \mathrm{C}\right)$ & -6.71 & -6.58 & -6.51 & -5.37 & -6.17 & -5.57 & -4.86 & -6.00 \\
\hline $\operatorname{Vmp}\left(\mathbf{m V} /{ }^{\circ} \mathrm{C}\right)$ & -7.19 & -7.16 & -7.07 & -5.89 & -6.42 & -6.37 & -6.58 & -7.24 \\
\hline $\operatorname{Jsc}\left(\mu \mathrm{A} / \mathrm{cm}^{2} /{ }^{\circ} \mathrm{C}\right)$ & 5.51 & 0.88 & 10.37 & 6.72 & 10.16 & 3.20 & 22.40 & 18.89 \\
\hline $\operatorname{Jmp}\left(\mu \mathrm{A} / \mathrm{cm}^{2} /{ }^{\circ} \mathrm{C}\right)$ & 0.69 & -4.45 & 4.93 & 0.79 & 9.22 & -0.38 & 6.63 & 9.66 \\
\hline
\end{tabular}




\subsection{SolAero Cells Measurement Comparison}

Tab. 2 shows BOL on-orbit temperature coefficients, and the I-V performance measurements compared to the pre-flight laboratory measurements made at SolAero corrected to AM0 and $28^{\circ} \mathrm{C}$. Across all cells, the laboratory measurements show higher Voc and Vmp values. This difference, between the on-orbit Voc and $\mathrm{Vmp}$ is likely due to systemic errors in determining the temperature of individual cells on-orbit. In the laboratory, temperature is well controlled and cells are at a uniform temperature. In space, where the thermal environment is driven by the changing view to the sun, the Earth, and deep space, the temperature of a cell maybe considerably different than the temperature sensor itself. This observation is consistent with the location of the temperature sensor being underneath the substrate face sheet. The front side of the face sheet with the cells being illuminated by the sun, will naturally be warmer than backside of the face sheet where the temperature sensor is located.

Further evidence for the systemic errors of the on-orbit temperature measurement, is the fact that the $4 \mathrm{~J}$-IMM cells show the greatest Voc difference implying the $4 \mathrm{~J}$ IMM cells are running hotter than other cells on the same panel. The 4J-IMM cells were the only cells not biased near their maximum power point (Pmax), but at Isc. This would cause the 4J-IMM cells to run hotter than those biased at Pmax, since $\sim 25 \%$ more of the solar energy would be converted to heat compared to other cells on the plate where the bias load would shed energy from the cell.

It is not unreasonable to argue that the laboratory Voc measurements and the on-orbit Voc should be very close in value if they were measured at the same temperature. If we assume that the laboratory measurements of temperature are more reliable than the on-orbit temperature measurements, we can use the temperature coefficients to calculate the implied temperature difference and adjust the I-V parameters accordingly.

Doing so, reduces the percentage difference between the lab and on-orbit power measurements to roughly the percentage differences in Imp, as the Vmp values are then in good agreement in most instances. That leaves approximately a $\pm 2 \%$ band around the on-orbit measurements, with the 3J-IMM large area cells consistently measured lower current values in the lab than on-orbit, and the $4 \mathrm{~J}-\mathrm{IMM}$ and the $3 \mathrm{~J}-\mathrm{IMM}$ strings measured as higher in current in the lab than the onorbit data would suggest. Given the uncertainty in the spectral content of the LAPSS and the lack of spectrally matched calibrated reference cells, the laboratory and on-orbit measurements are remarkably close.

\subsection{Spectrolab Cells Measurement Comparison}

The Spectrolab coupons were measured in much the same way in the laboratory as the SolAero panels. That is, with calibrated $\mathrm{GaInP} / \mathrm{GaAs} / \mathrm{Ge}$ isotype cells,

Table 3. On-orbit performance parameters (BOL) and temperature coefficients compared to laboratory pre-flight ground measurements (GRD) for Spectrolab cells.

\begin{tabular}{|c|c|c|c|c|c|c|c|c|c|}
\hline $\begin{array}{c}\text { BOL at } 22^{\circ} \mathrm{C} \& \\
28^{\circ} \mathrm{C}, \text { GRD at } \\
22^{\circ} \mathrm{C} \& 28^{\circ} \mathrm{C}\end{array}$ & $\begin{array}{l}22^{\circ} \mathrm{C} \\
\text { SBT }\end{array}$ & $\begin{array}{l}22^{\circ} \mathrm{C} \\
\text { SBT }\end{array}$ & $\begin{array}{l}22^{\circ} \mathrm{C} 4 \mathrm{JJ}- \\
\text { IMM }\end{array}$ & $\begin{array}{l}22^{\circ} \mathrm{C} 4 \mathrm{~J}- \\
\text { IMM }\end{array}$ & $\begin{array}{l}22^{\circ} \mathrm{C} \\
\text { UTJ }\end{array}$ & $\begin{array}{l}22^{\circ} \mathrm{C} \\
\mathrm{UTJ}\end{array}$ & $\begin{array}{l}28^{\circ} \mathrm{C} 3 \mathrm{~J}- \\
\text { IMM string }\end{array}$ & $\begin{array}{l}28^{\circ} \mathrm{C} 3 \mathrm{~J}- \\
\text { IMM string }\end{array}$ & $\begin{array}{l}28^{\circ} \mathrm{C} \text { Large } \\
\text { Area 3J-IMM }\end{array}$ \\
\hline BOL Pwr Watts) & 0.0372 & 0.0384 & 0.153 & 0.155 & 0.982 & 1.010 & 0.571 & 0.541 & 0.736 \\
\hline GRD Pwr (Watts) & 0.0368 & 0.0352 & 0.155 & 0.156 & 0.996 & 1.001 & 0.588 & 0.596 & 0.765 \\
\hline BOL Voc (Volts) & 4.785 & 4.673 & 4.354 & 4.326 & 2.644 & 2.643 & 8.657 & 8.721 & 2.872 \\
\hline GRD Voc (Volts) & 4.680 & 4.660 & 4.300 & 4.320 & 2.700 & 2.670 & 8.88 & 8.83 & 2.93 \\
\hline BOL Isc (Amps) & 0.0097 & 0.0097 & 0.0409 & 0.0415 & 0.4633 & 0.4575 & 0.0843 & 0.0827 & 0.337 \\
\hline GRD Isc (Amps) & 0.0097 & 0.0096 & 0.0420 & 0.0420 & 0.4600 & 0.4540 & 0.083 & 0.082 & 0.33 \\
\hline BOL Imp (Amps) & 0.0090 & 0.0094 & 0.0396 & 0.0402 & 0.4254 & 0.4353 & 0.0757 & 0.0725 & 0.305 \\
\hline GRD Imp (Amps) & 0.0090 & 0.0090 & 0.0400 & 0.0400 & 0.4240 & 0.4240 & 0.076 & 0.077 & 0.31 \\
\hline BOL Vmp (Volts) & 4.157 & 4.085 & 3.875 & 3.859 & 2.309 & 2.321 & 7.547 & 7.458 & 2.415 \\
\hline GRD Vmp (Volts) & 4.090 & 3.910 & 3.870 & 3.890 & 2.350 & 2.360 & 7.73 & 7.74 & 2.50 \\
\hline \multicolumn{10}{|c|}{$\begin{array}{l}\text { Percent difference of the ground based measurement compared } \\
\text { to the on-orbit measurement (minus sign, red) = lower than on-orbit }\end{array}$} \\
\hline \% diff Power & -1.2 & -8.5 & 0.9 & 0.3 & 1.4 & -1.0 & 2.9 & 10.2 & 3.9 \\
\hline$\%$ diff Voc & -2.2 & -0.3 & -1.2 & -0.1 & 2.1 & 1.0 & 2.6 & 1.2 & 2.0 \\
\hline$\%$ diff Isc & 0.3 & -1.3 & 2.6 & 1.3 & -0.7 & -0.8 & -1.5 & -0.8 & -1.3 \\
\hline$\%$ diff Imp & 0.5 & -4.4 & 1.0 & -0.5 & -0.3 & -2.6 & 0.4 & 6.2 & 0.3 \\
\hline$\%$ diff Vmp & -1.6 & -4.3 & -0.1 & 0.8 & 1.8 & 1.7 & 2.4 & 3.8 & 3.5 \\
\hline \multicolumn{10}{|c|}{ On-orbit measured temperature coefficients } \\
\hline Voc $\left(\mathrm{mV} /{ }^{\circ} \mathrm{C}\right)$ & -10.66 & -10.55 & -8.08 & -8.25 & -6.04 & -5.66 & -5.94 & -5.38 & -5.33 \\
\hline $\mathrm{Jsc}\left(\mu \mathrm{A} / \mathrm{cm} 2 /{ }^{\circ} \mathrm{C}\right)$ & 1.75 & 1.98 & 7.75 & 4.20 & 8.19 & 12.76 & 2.24 & 6.40 & 13.36 \\
\hline $\operatorname{Jmp}\left(\mu \mathrm{A} / \mathbf{c m} 2 /{ }^{\circ} \mathrm{C}\right)$ & 8.49 & 2.88 & 7.47 & 4.04 & 7.03 & 5.72 & 1.45 & 5.19 & 8.10 \\
\hline $\operatorname{Vmp}\left(\mathrm{mV} /{ }^{\circ} \mathrm{C}\right)$ & -10.02 & -9.88 & -8.22 & -8.46 & -6.55 & -6.46 & -6.43 & -5.31 & -5.63 \\
\hline
\end{tabular}


without using a spectral correction between the cells under test and the calibrated standards. As before, this type of measurement relies on having a high fidelity solar simulator to make these measurements meaningful. The laboratory measurements in this case were made at two different temperatures, with most cells measured at $22^{\circ} \mathrm{C}$ and several measured at $28^{\circ} \mathrm{C}$. For the results presented, in Tab. 3, the on-orbit data was corrected to the temperature of the laboratory results. There are several interesting observations to make regarding the comparative results.

As a whole, the laboratory measurements are again, remarkably close to the on-orbit measurements with just two outliers. Unlike the SolAero cells where the laboratory Voc values were all higher than the on-orbit measurements, the Spectrolab cells show an even mix of higher and lower Voc values. It is still likely though, that the on-orbit temperature sensor does not faithfully represent the temperature of each cell as well as in the laboratory.

The outliers, one of the SBT cells, is significantly lower than on-orbit, and one of the 3J-IMM strings significantly higher, are interesting because the Vmp values are further off than the Voc values, so one cannot immediately attribute the difference to temperature differences between the lab and on-orbit. Likewise, the Imp values are significantly further off than the Isc values. Since both Imp and Vmp are off, and temperature seems an unlikely cause, it suggests that spectral current matching maybe more of an issue for these two cells. If this is so, it makes the case for obtaining calibrated isotype cells for the cell under test or fully characterizing the spectral content of the LAPSS for performing a spectral mismatch correction.

\section{SUMMARY}

The FTSCE III on-orbit data of IMM and other advanced multi-junction technologies have been analysed and compared to the pre-flight measurements. Given the lack of calibration standards for these cell types, laboratory measurements were successful at predicting the BOL performance of these cells. There were however errors attributed to temperature discrepancies between on-orbit and the laboratory, and potentially a lack of spectral matching between LAPSS systems and AM0.

Acknowledgement: This work was supported by the United States Air Force Research Laboratory, Space Vehicles Directorate.

\section{REFERENCES}

1. Cho, B., Lutz, R., Pappan, J., Downard, E., Cornfeld, A., Fatemi, N., Stan, M.A., Sharps, P., Su, C., Billets,
S., Gasner, S., Howard, A., "IMM experimentation in the next frontier: Emcore's participation in the MISSE-8 program," 35th IEEE Photovoltaic Specialists Conference pp.110-112, 20-25 June 2010

2. A. B. Cornfeld, M. Stan, T. Varghese, J. Diaz, A. V. Ley, B. Cho, A. Korostyshevsky, D. J. Aiken and P. R. Sharps, "Development of a large area inverted metamorphic multi-junction (IMM) highly efficient AM0 solar cell," $33^{\text {rd }}$ IEEE Photovoltaic Specialists Conference, 11-16 May 2008

3. A. B. Cornfeld, D. Aiken, B. Cho, A. Vance Ley, P. Sharps, M. Stan, T. Varghese, "Development of a four sub-cell inverted metamorphic multi-junction (IMM) highly efficient AM0 solar cell," 35th IEEE Photovoltaic Specialists Conference pp.105-109, 20-25 June 2010

4. D. C. Law, X. Q. Liu, J. C. Boisvert, E. M. Redher, C. M. Fetzer, S. Mesropian, R. R. King, K. M. Edmondson, B. Jun, R. L. Woo, D. D. Krut, P. T. Chiu, D. M. Bhusari, S. K. Sharma, N. H. Karam, "Recent progress of Spectrolab high-efficiency space solar cells," 38th IEEE Photovoltaic Specialists Conference pp. 3146-3149, 3-8 June 2012

5. P. T. Chiu, D. C. Law, R. L. Woo, S. B. Singer, D. Bhusari, W. D. Hong and A. Zakaria, J. Boisvert, S. Mesropian, R. R. King, N. H. Karam, "35.8\% space and $38.8 \%$ terrestrial $5 \mathrm{~J}$ direct bonded cells," 40th IEEE Photovoltaic Specialists Conference pp. 11-13, 8-13 June 2014

6. M. Krasowski, L. Greer, J. Flatico, P. Jenkins, D. Spina, "A Hardware and Software Perspective of the Fifth Materials on the International Space Station Experiment (MISSE-5)," NASA Technical Memorandum, NASA/TM-2005-213840, August, 2005.

7. Michael J. Krasowski, Norman F. Prokop, Joseph M. Flatico, Lawrence C. Greer, Phillip P. Jenkins, Philip G. Neudeck, Liangyu Chen, and Danny C. Spina, "CIB: An Improved Communication Architecture for Real-Time Monitoring of Aerospace Materials, Instruments, and Sensors on the ISS," The Scientific World Journal, vol. 2013, Article ID 185769, 12 pages, 2013. doi:10.1155/2013/185769.

8. Clay H. Seaman, "Calibration of solar cells by the reference cell method-The spectral mismatch problem," Solar Energy, Volume 29, Issue 4, 1982, Pages 291-298, ISSN 0038-092X, 